\title{
Energos, um objeto de aprendizagem para o debate escolar sobre os meios de produção de energia elétrica.
}

\author{
Marcelo Leandro Eichler ${ }^{1}$ \\ Gabriela Trindade Perry ${ }^{* *}$ \\ Mário Régis Gonçalves* \\ José Claudio Del Pino*
}

Resumo: A temática sobre os meios de produção de energia elétrica e seus possíveis impactos ambientais e sociais está presente em diversos documentos oficiais com orientações curriculares para a escola básica. Neste artigo, apresenta-se um objeto de aprendizagem que aborda esta temática, descreve-se seu projeto pedagógico e analisa-se sua implementação computacional. Indica-se, também, uma estratégia pedagógica para a sua utilização, o jogo de representação de papéis. Nesse sentido, defende-se a preponderante ação do professor na condução dessa estratégia.

Palavras-chave: objeto de aprendizagem; jogo de representação de papéis; matriz energética.

Abstract: [The use of a learning object like Energos for the discussion on the means of production of electrical energy]. The means of production of electrical energy and their possible environmental and social impacts is a theme that is present in curriculum guidelines for the basic school stated in many official documents. This paper presents Energos, a learning object that approaches such a theme. The pedagogical project of Energos is described and its computational implementation is analyzed. The pedagogical strategy of role-playing game is suggested to employ such a learning object. In this sense, this paper highlights the importance of the actions taken by the teacher on the conduction of such a strategy.

Keywords: learning object; role playing game; electricity generation.

\footnotetext{
${ }^{1}$ Licenciado em Química e Doutor em Psicologia do Desenvolvimento pela UFRGS, é professor da UERGS e pesquisador da Área de Educação Química (AEQ) da UFRGS. Autor correspondente: exlerbr@yahoo.com.br ** Bacharel em Design, com habilitação em Programação Visual, pela ULBRA, é doutoranda em Informática Educativa pela UFRGS.

*** Licenciado em Geografia, é professor do Colégio Cristo Redentor da ULBRA.

**** Licenciado em Química PUC-RS, Especialista em Ensino de Química UCS, Doutor em Química de Biomassa UFGRS, é professor do Instituto de Química e coordenador da AEQ-UFRGS.
} 
$\underline{\text { Introdução }}$

No Brasil e no Mundo, muitos administradores públicos, consultores e governantes se perguntam sobre em quais meios de produção de energia elétrica se deve investir. As diversas formas de produzir energia elétrica possuem possíveis impactos ambientais diferentes. Quando se escolhe uma ou mais formas de produzir energia elétrica elas tem reflexo na organização da sociedade e na vida das pessoas. Esse debate aparece constantemente nos meios de comunicação, como jornais, revistas e televisão. As opiniões são diversas, às vezes contraditórias e às vezes há consenso.

O tema "energia elétrica" e os conhecimentos sobre os modos convencionais e alternativos de sua produção são sugeridos nos seguintes Parâmetros Curriculares Nacionais: a) PCN Transversal Meio Ambiente (Brasil, 2001); b) PCN Geografia (Brasil, 1998); c) PCNEM Ciências Humanas e suas Tecnologias (Brasil, 2006b); e d) PCNEM Ciências da Natureza, Matemática e suas Tecnologias (Brasil, 2006a).

Energos é um objeto de aprendizagem que aborda os meios de produção de energia elétrica e seus possíveis impactos ambientais e sociais. O objeto é uma simulação da realidade e foi elaborado através de adaptações da matriz energética do Estado do Espírito Santo e dos mapas (microrregiões, relevo, eólico e de insolação) do Estado do Rio Grande do Sul (Eichler e Del Pino, 2006; Eichler, Gonçalves, Silva, Junges e Del Pino, 2003; Gonçalves, Eichler e Del Pino, 2002 e 2003). O objeto pode ser acessado em www.iq.ufrgs.br/aeq/energos.

Energos pode ser utilizado de formas diferentes, mas recomendamos que ele seja usado para auxiliar o debate escolar, em diferentes níveis de ensino, sobre os meios de produção de energia elétrica. Os mapas servem para ilustrar, principalmente, as características de relevo, hidrografia e insolação de Energos (na Figura 1 pode-se ver a tela com o mapa das regiões de Energos). Os depoimentos e a hemeroteca têm por objetivo ilustrar a multiplicidade de opiniões que existe na realidade sobre os meios de produção de energia elétrica. Utilizando Energos, um(a) certo(a) aluno(a) poderá se posicionar em relação a esse debate, preferindo algum(ns) meio(s) de produção de energia elétrica em detrimento de outro(s). Entretanto, uma outra pessoa que utilize Energos poderá chegar a uma conclusão diferente. Esse é o objetivo do debate escolar: provocar o encontro de opiniões e a reflexão sobre as opiniões de acordo e de desacordo. Energos têm, portanto, objetivo de auxiliar o debate escolar sobre os meios de produção de energia elétrica.

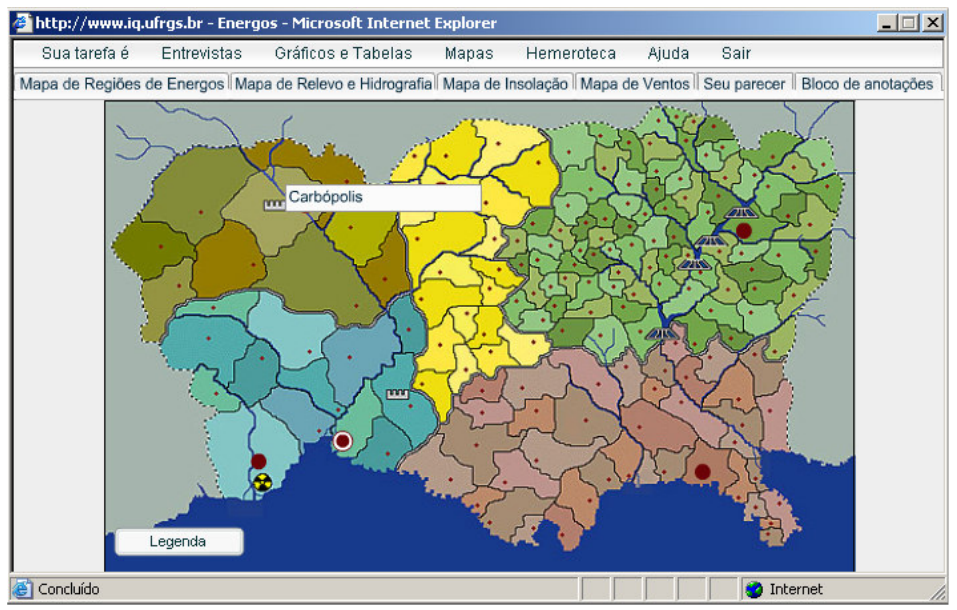

Figura 1 - Tela com mapa das regiões de Energos. 
$\mathrm{Na}$ próxima secção, abordaremos o projeto pedagógico do objeto de aprendizagem, deixando para outras secções uma breve análise sobre os problemas surgidos durante sua implementação computacional (realizada em Flash e PHP) e uma orientação pedagógica para a utilização de Energos, envolvendo os jogos de representação de papéis.

Algumas considerações sobre o projeto pedagógico de Energos

O objeto de aprendizagem Energos tem por objetivo apoiar o estudo dos meios convencionais e alternativos de produção de energia elétrica e seus possíveis impactos ambientais e sociais. No texto de introdução do objeto é feita a orientação para sua utilização. Utiliza-se uma metáfora em que o(a) aluno(a) é declarado(a) um conselheiro(a) do Conselho Nacional de Desenvolvimento Econômico e Social de Energos. Na Figura 2, pode-se ver a tela de abertura do objeto de aprendizagem.

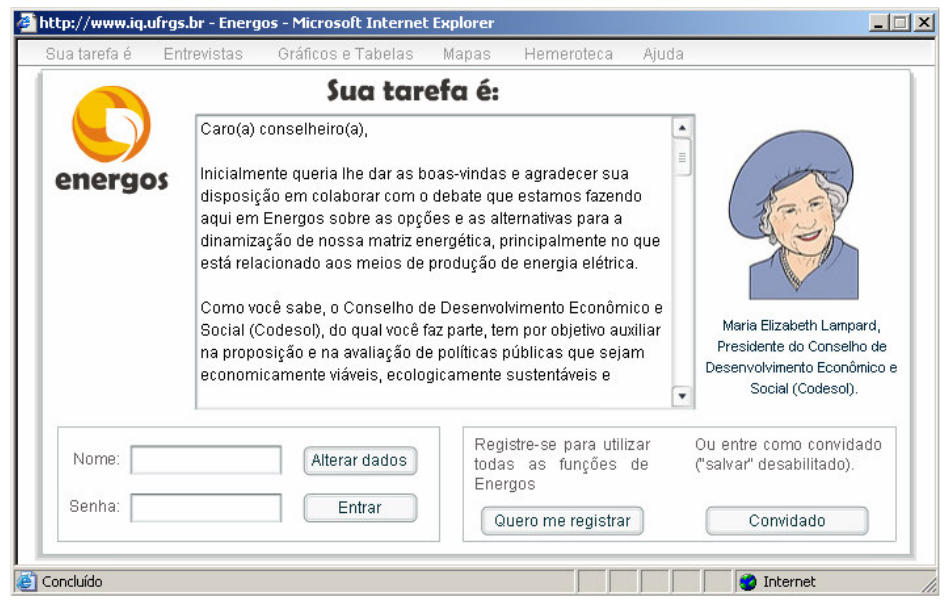

Figura 2 - Tela de entrada de Energos.

$\mathrm{Na}$ atividade de encerramento, propõe-se que o(a) aluno(a) rediga um parecer, a ser enviado ao seu(sua) professor(a), que irá subsidiar o debate escolar. Na Figura 3, pode-se ver a tela do objeto com a atividade de encerramento. Nesse parecer, o(a) usuário(a) precisa responder questões que envolvem os seguintes assuntos:

a) a decisão sobre o meio convencional (hidrelétrica, termoelétrica ou termonuclear) de produção de energia elétrica que será ampliado em Energos;

b) a decisão sobre os meios alternativos de produção de energia elétrica, para cada uma das cinco regiões de Energos, que serão desenvolvidos.

c) e as melhores justificativas que ele(a) tenha encontrado para apoiar suas decisões (por exemplo, o(a) aluno(a) pode apoiar suas decisões em argumentos encontrados nos depoimentos com os moradores de Energos ou encontradas nas reportagens armazenadas na hemeroteca).

Como se pode depreender do parêntese anterior, a utilização de Energos envolve bastante leitura, assim é necessário que o(a) professor(a) ressalte a importância da leitura, um compromisso de todas as disciplinas escolares (Neves, Souza, Schäffer, Guedes e Klüsener, 1998), e a atenção que os(as) aluno(as) devem ter durante a navegação no objeto de aprendizagem.

A hemeroteca contém 79 reportagens de jornais e revistas. Energos começou a ser desenvolvido em 2000. Nesse período foram publicadas diversas notícias sobre a crise energética brasileira e sobre os meios convencionais e alternativos de produção de energia elétrica. Muitas dessas notícias nós armazenamos. Posteriormente, para concluir 
os textos apresentados na hemeroteca procuramos notícias publicadas pela Agência Brasil (www.agenciabrasil.gov.br), que é uma agência de notícias vinculada à Radiobrás, e consultamos a hemeroteca do Instituto de Eletrotécnica e Energia da Universidade de São Paulo (http://infoener.iee.usp.br). Muitas notícias foram adaptadas para os propósitos do debate escolar, que é o objetivo de Energos. As adaptações foram realizadas com a modificação de cidades e de pessoas que eram citadas nas notícias. Nas adaptações realizadas incluímos os personagens, bem como suas imagens, e as cidades de Energos. Entretanto, muitas notícias foram reproduzidas praticamente na íntegra (sempre adequadamente citadas as fontes e datas). Nesses casos, incluímos imagens de domínio público, encontradas na Internet.

Assim, consideramos que é oferecida uma elevada quantidade de informações aos(às) alunos(as). Nesse sentido, entendemos que um determinado grupo de alunos(as) buscará mais por um tipo de informação que outro grupo. Essa multiplicidade de acesso à informação é que pode ser ressaltado pelo(a) professor(a), para posteriormente discutir com os(as) alunos(as) as notícias que eles leram e o que eles compreenderam do que leram.

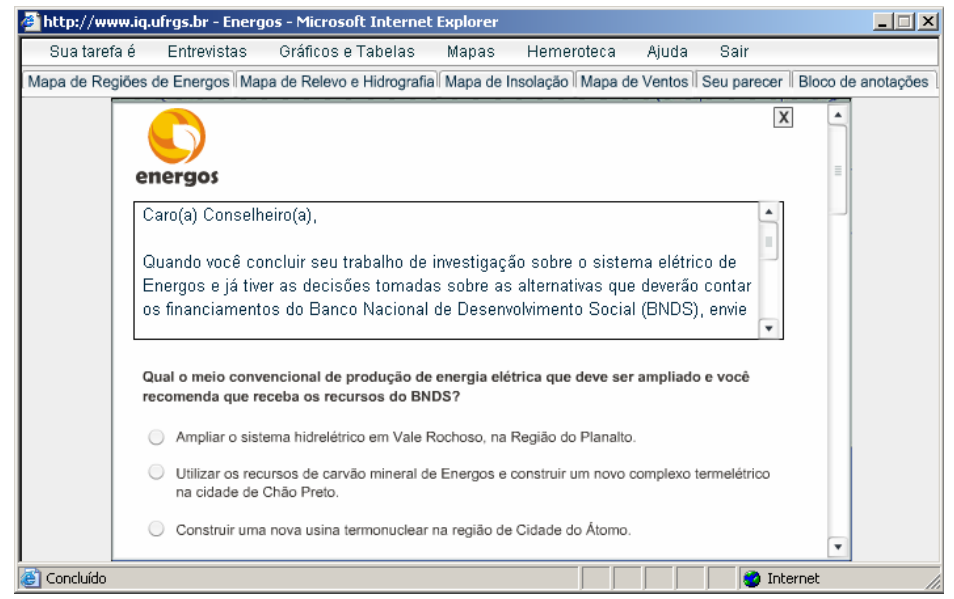

Figura 3 - Tela com o parecer a ser preenchido pelo usuário.

Os depoimentos dos personagens apresentados em Energos são um outro conjunto de textos que auxilia o(a) aluno(a) a situar o problema e oferece algumas sugestões para a sua solução. A criação dos textos de depoimentos desses personagens, escritos pelo primeiro autor deste artigo, teve como fundamento a idéia de propiciar aos usuários de Energos o acesso à multiplicidade de vozes e de papéis sociais que estão envolvidos pela temática da produção de energia elétrica. As ilustrações dos personagens foram retiradas de um banco de imagens, do Corel Draw ${ }^{\circledR}$, de figuras históricas, como políticos, pintores, escritores e cientistas, por exemplo. Na Figura 4, pode-se ver uma tela com o depoimento do presidente do Sindicato dos Trabalhadores Rurais da Encosta, no município de Rochele do Norte, senhor Hugo van Basten.

Geralmente os materiais didáticos computacionais (como os softwares educativos e os objetos de aprendizagem) são acompanhados por uma ferramenta de hipertexto (helpfiles ou biblioteca de ajuda). Entretanto, devido ao desenvolvimento dos recursos disponibilizados em rede pela Internet, julgamos que essas necessidades são hoje em dia supridas pela Wikipédia (http://pt.wikipedia.org.), que é uma enciclopédia multilingüe online livre e colaborativa, ou seja, escrita por várias pessoas, todas elas voluntárias. Dessa forma, procuramos propiciar a conversão de ferramentas e indicamos 
aos usuários a navegação pela enciclopédia quando ele(a) sentir a necessidade de maiores informações, quiser tirar dúvidas em relação a certos conceitos apresentados em Energos ou, mesmo, saciar sua curiosidade.

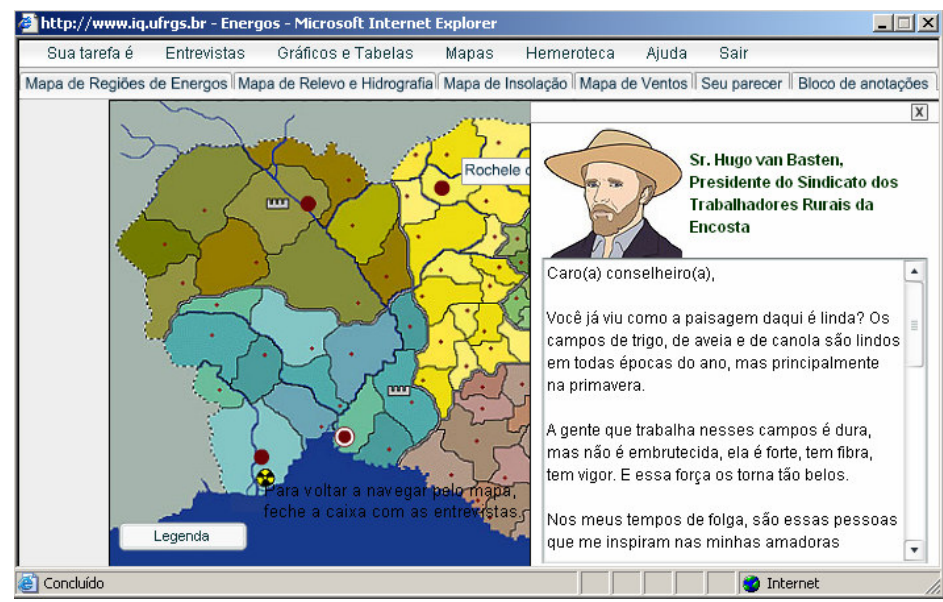

Figura 4 - Tela com depoimento de um dos personagens.

O tempo previsto da atividade depende do uso que o(a) professor(a) fizer do objeto de aprendizagem. Sugerimos que seja feito um debate escolar, através de jogos de representação de papéis, após a utilização individual ou em duplas do objeto de aprendizagem. Nesse sentido, por exemplo, imaginamos que alunos do ensino médio possam levar cerca de 2 horas/aula na navegação do objeto de aprendizagem. O jogo de representação de papéis envolveria outras 2 horas/aula. Em uma próxima secção, descreveremos a estratégia pedagógica de representação de papéis.

Além disso, Energos tem uma proposta interdisciplinar, por isso, por exemplo, sua adequação ao PCN Transversal Meio Ambiente. Dessa forma, professores(as) de diferentes disciplinas podem utilizar o objeto de aprendizagem em atividades complementares aos períodos de sala de aula, por exemplo, em atividades extra-classe ou através de grupos de estudos.

Alguns problemas na implementação computacional do objeto de aprendizagem

Em sua maior parte, Energos foi implementado em Flash. O objeto de aprendizagem possui duas versões, uma contendo banco de dados, outra não. Foram realizadas duas versões para permitir que o objeto de aprendizagem seja utilizado de diferentes formas nas diversas realidades de escola. Na versão com banco de dados, que pode ser utilizada em rede, é possível fazer o cadastramento de um usuário e do e-mail do(a) professor(a) para qual será enviado o parecer depois de preenchido. Essa versão conta, ainda, com o um bloco de notas, no qual o usuário pode anotar ou copiar as informações que julgar úteis para responder as questões presentes no parecer. A versão sem banco de dados não possui essas funcionalidades e é distribuída com um arquivo executável, que possibilita a utilização do objeto de aprendizagem sem os recursos de rede e sem necessidades de configuração do sistema.

$\mathrm{Na}$ versão com banco de dados, foi utilizado o banco MYSQL e PHP, para fazer a conexão entre o banco de dados e o Flash. A implementação computacional foi realizada entre março e novembro de 2006 pela segunda autora deste artigo.

Os componentes de interface de Energos contêm:

a) Tela de entrada: onde o usuário pode se logar, criar e alterar seu cadastro ou entrar como convidado. O cadastramento é importante, pois nele será 
inserido o endereço de e-mail do(a) professor(a) para ser enviado o parecer preenchido pelo(a) aluno(a).

b) Menu, com as seguintes possibilidades oferecidas: Sua Tarefa é...,

Entrevistas, Gráficos e Tabelas, Mapas, Hemeroteca, Ajuda e Sair.

c) Abas de navegação, com mapas (de regiões, de relevo e hidrografia, de insolação e de ventos) com botões de legendas, bloco de anotações e formulário de parecer.

d) Áreas ativas em certas cidades sobre o mapa, a partir das quais são abertas janelas de diálogo em que se podem escolher as entrevistas a serem realizadas.

Nesta secção, descrevemos alguns problemas encontrados e solucionados durante a etapa de implementação do objeto de aprendizagem. Os dados desta secção foram obtidos através da análise dos e-mails trocados pelos dois primeiros autores do artigo, o primeiro elaborou o projeto pedagógico e a segunda realizou a implementação computacional. Nesse sentido, aqui o objetivo é mostrar os diversos problemas que a equipe enfrentou durante o desenvolvimento do aplicativo. Acreditamos que a observação e análise de dados históricos sobre os problemas surgidos durante a implementação computacional de um aplicativo podem subsidiar estratégias que busquem evitar tais problemas no desenvolvimento de futuros projetos.

Em relação às etapas anteriores à programação, isto é, ao objetivo pedagógico, a estratégia instrucional e até mesmo o funcionamento e a aparência estavam razoavelmente definidos. Na etapa de elaboração do projeto pedagógico, para conferir maior veracidade e permitir uma analogia com a situação da matriz energética do estado do Rio Grande do Sul, foram feitos mapas ilustrativos com o auxílio de um geógrafo (Gonçalves, Eichler e Del Pino, 2002 e 2003). Ressalta-se este ponto porque não é incomum começar a codificação com a parte relacionada ao design instrucional ainda em aberto, o que aumenta consideravelmente a dificuldade em gerenciar um projeto, pois os requisitos mudam a todo o tempo. Outra questão que serve de norte para avaliar o grau de desafio que o aplicativo oferecia, do ponto de vista da implementação, é o grau de sofisticação da interface e da interação em Energos, que podem ser consideradas de baixa ou de média complexidade.

Nenhum aplicativo, do mais simples ao mais complexo, é isento de problemas durante seu desenvolvimento. Diversas ações podem ser feitas para tentar minimizar tais problemas, por exemplo: pode-se adotar um padrão de design de projeto ou pode-se viabilizar ações de design participativo, fazendo com que todos os membros participem da construção da aparência da interface. Essas indicações são encontradas na literatura em programação de aplicativos que utilizam orientação a objeto e ergonomia/design. Mesmo assim, os problemas continuaram existindo, como em qualquer outro processo.

Depois de encerrado o desenvolvimento de Energos, e talvez por já termos passado por essa situação tantas vezes ${ }^{2}$, percebeu-se que estes mesmos problemas podem ser utilizados como indicadores da "saúde" do processo como um todo. Assim, supõe-se que há uma relação entre os tipos de problemas e a(s) ação(ões) que podem ser tomadas para precavê-los, o que permitiria uma análise bem embasada do processo de desenvolvimento, possibilitando uma alocação mais justa de recursos.

Entre as possíveis fontes de problemas pode-se listar:

1. falhas na comunicação, mudanças de rumo $->$ relacionadas ao projeto visual $e$ ergonomia;

\footnotetext{
${ }^{2}$ Os autores deste artigos participaram da elaboração de diversos materiais didáticos computacionais, tais como, Carbópolis e Cidade do Átomo (Marcelo Eichler e José Claudio Del Pino) e Equil (Gabriela Perry).
} 
2. erros de programação (mau funcionamento, bugs) -> relacionados à arquitetura do aplicativo;

3. descuidos e esquecimentos (por exemplo: alertas que não disparam, falta de campos em um formulário, falta de títulos em imagens) $->$ relacionados à arquitetura do aplicativo; e

4. limitações técnicas de ferramentas e de instalação -> limitações inerentes à implementação.

A Figura 5 mostra a distribuição dos tipos de problemas de acordo com o mês.

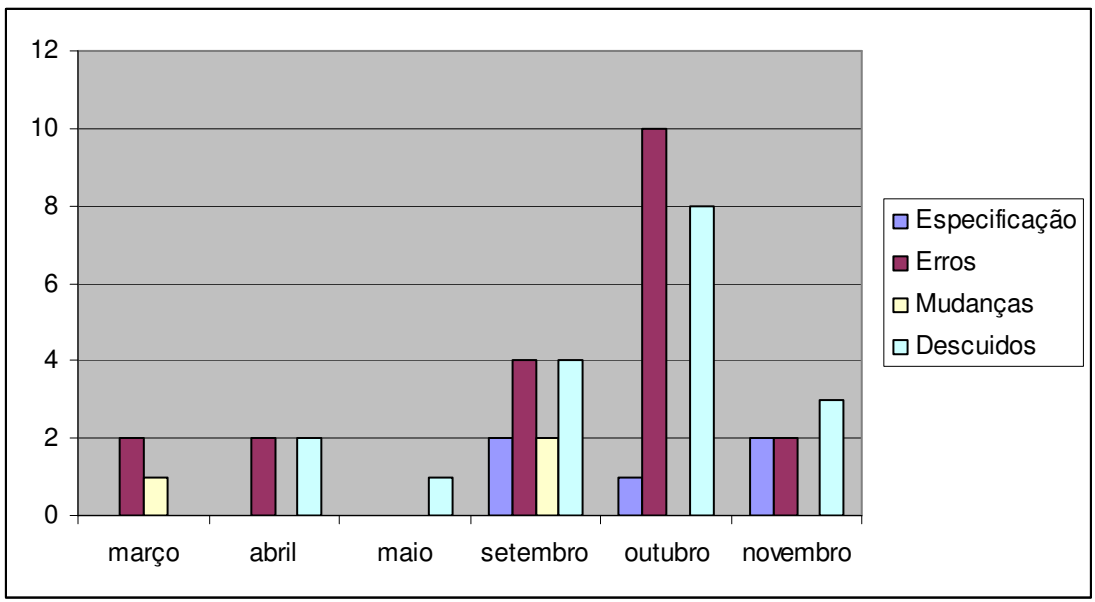

Figura 5 - Distribuição dos tipos de problemas encontrados de acordo com o mês.

O quadro a seguir mostra excertos de relatórios, extraídos dos e-mails trocados entre os dois primeiros autores deste artigo durante a implementação computacional do objeto de aprendizagem. Os exemplos apresentam três tipos de problemas classificados como "erros de programação".

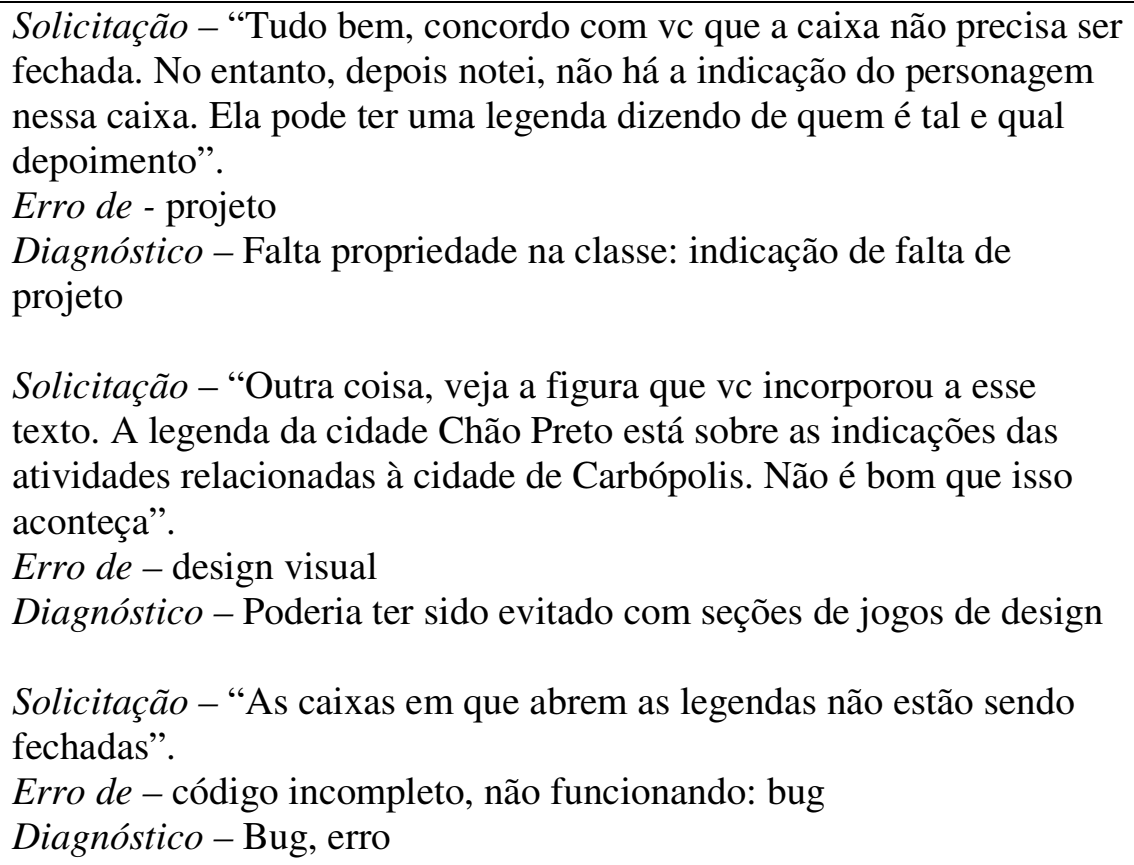
fechada. No entanto, depois notei, não há a indicação do personagem nessa caixa. Ela pode ter uma legenda dizendo de quem é tal e qual depoimento".

Erro de - projeto

Diagnóstico - Falta propriedade na classe: indicação de falta de projeto

Solicitação - "Outra coisa, veja a figura que vc incorporou a esse texto. A legenda da cidade Chão Preto está sobre as indicações das atividades relacionadas à cidade de Carbópolis. Não é bom que isso aconteça".

Erro de - design visual

Diagnóstico - Poderia ter sido evitado com seções de jogos de design

Solicitação - "As caixas em que abrem as legendas não estão sendo fechadas".

Erro de - código incompleto, não funcionando: bug

Diagnóstico - Bug, erro

Quadro 1 - Exemplos de erros de programação 
No caso de Energos, acredita-se que o principal responsável pela geração de problemas foi a não adequação do framework, ou o uso incorreto da metodologia. Provavelmente, pelos seguintes motivos: a) falta de domínio em projetos orientado a objetos, b) inserção de novos requisitos durante a etapa de implementação e c) falta de controle da lista TO-DO (coisas a fazer). Isso fez com que o código do programa perdesse a forma aos poucos, se tornando de difícil manutenção. $\mathrm{O}$ fato de haver duas versões do programa, com e sem banco de dados, contribui para esta situação.

Assim, analisando os tipos de erros reportados para Energos, percebe-se a falta de comprometimento com uma arquitetura, com um design da aplicação. Com o objetivo de minorar estes problemas, planeja-se adotar em novos projetos o padrão MVC (model-vision-control), sugerido pela literatura técnica especializada (Moock, 2005) como o mais indicado para aplicativos com grande quantidade de interação e interfaces com o usuário de alta complexidade. Espera-se que a adoção deste padrão facilite a fidelidade ao design da aplicação, o que não foi mantido nas versões distribuídas de Energos.

Nesta secção, tivemos como intenção apontar alguns dos problemas surgidos durante a implementação e indicar suas possíveis causas. Uma vez que a classificação dos tipos de problemas foi realizada depois de terminado o aplicativo, não conseguimos utilizar categorias bem definidas nessa classificação, nem possuímos dados suficientes para realizar uma análise mais fidedigna. Nesse sentido, este é um objetivo para um próximo projeto em que estamos envolvidos: estabelecer uma metodologia de categorização de problemas e de coleta de dados durante o desenvolvimento de aplicativos educacionais, para verificar a relação entre os mesmos e etapas anteriores à codificação. Entre os exemplos de dados que deverão ser coletados estão: hora gasta por componente, tempo entre solicitação e entrega e quantidade de vezes que o componente foi alterado. Esses objetivos serão perseguidos durante a implementação de Energos Plus, que descrevemos na última secção deste artigo.

\section{Os jogos de representação de papéis}

$\mathrm{Na}$ introdução, sugerimos que após a utilização do objeto de aprendizagem Energos seja realizado um debate entre os alunos. Esse debate pode ocorrer sob diferentes estratégias didáticas, aqui queremos apresentar a estratégia do jogo de representação de papéis (role-playing game, ou RPG, em inglês). Nesse caso, é interessante abordar, ainda que brevemente, alguns conceitos relacionados aos jogos de representação de papéis.

A estratégia pedagógica de representação de papéis é um tema bastante disseminado na literatura em inglês (Blatner, 2002; Bonnet, 2000, Cronin-Jones, 2000; Duveen e Solomon, 1994; Jackson e Walters, 2000; Maier, 1991; Trumbore, 1974; Whisnant, 1992), entretanto para esse tema se encontra pouco material em português (basta procurar, por exemplo, as expressões "jogo de representação de papéis" e "educação" no Google e verificar a pequena quantidade de remissivas que serão encontradas). Por outro lado, vimos buscando a indicação da utilização dessa estratégia didática com a utilização de um software que produzimos sobre energia nuclear (Eichler, Junges e Del Pino, 2005 e 2006).

A representação de papéis é um método para a exploração de assuntos em situações sociais complexas e polêmicas (Blatner, 2002). Dessa forma, ela pode ser utilizada para o treinamento profissional (por exemplo, a formação de pilotos da aviação civil ou treinamento de militares em jogos de guerra) ou em salas de aula para a compreensão de literatura, história ou ciência. A seguir, abordamos algumas 
recomendações para o planejamento e desenvolvimento de atividades de representação de papéis.

Inicialmente, é necessário diferenciar as atividades por representação de papéis dos simples debates com finalidades educacionais (Cronin-Jones, 2000). Essas estratégias são semelhantes, pois ambas podem priorizar um problema que ainda não foi resolvido pela sociedade, como, por exemplo: o aquecimento global, a poluição das águas, a engenharia genética, o desmatamento e o crescimento populacional. Nesse sentido, também, ambas estratégias podem auxiliar os(as) estudantes a praticar a comunicação verbal e a busca de informações. Porém, elas se diferenciam na amplitude dos vieses que são postos em discussão.

Os debates envolvem apenas dois grupos de estudantes, os que possuem opinião favorável ao tema em debate e aqueles que têm opinião contrária. Por exemplo, fazer um debate sobre energia nuclear, consistiria em perguntar aos alunos se eles são contra ou a favor a produção de energia nuclear e evidenciar seus motivos. Pode-se notar que essa abordagem é polarizada e pode favorecer pensamentos de tipo dualístico, no qual se acreditaria que para os assuntos em debate haveria apenas duas posições, uma sendo considerada certa e a outra errada.

Dessa maneira, diferente dos debates, as atividades de representação de papéis envolvem no mínimo quatro grupos de estudantes, com diferentes pontos de vista e perspectivas. Essas atividades são apoiadas por um cenário, que pode conter uma descrição real ou hipotética do assunto a ser abordado, do problema a ser resolvido ou evitado. O cenário deve claramente descrever a temática em questão e identificar os personagens que estão envolvidos na representação de papéis. Os personagens podem ser poucos, como quatro ou cinco, reunindo grupos de estudantes, ou muitos, como um por estudantes.

No caso de Energos, o(a) aluno(a) é declarado(a) um conselheiro(a) do Conselho Nacional de Desenvolvimento Econômico e Social de Energos. No objeto de aprendizagem, propõem-se que o(a) aluno(a) escreva um parecer que irá subsidiar a discussão em uma próxima reunião ordinário do Conselho. Portanto, os personagens da atividade de representação de papéis podem ser criados através de uma decisão sobre quais seriam os participantes desse Conselho. Além disso, podem ser utilizados os próprios personagens que aparecem em Energos. Esses personagens podem ser definidos entre o(a) professor(a) que conduz a atividade e seus(suas) alunos(as).

O próximo ponto é desenvolver orientações que sumarizem as questões-chave e os argumentos que poderão ser apresentados pelos personagens. Essa orientação pode incluir as seguintes questões:

1) Sua posição é favorável ou contrária ao assunto?

2) Que argumentos suportam sua posição?

3) Que outros indivíduos, grupos ou organizações você considera que concordam com sua posição?

4) Que outros indivíduos, grupos ou organizações você acredita que discordam de sua posição?

5) Quais são alguns argumentos contrários a sua posição?

6) Como você poderia responder a esses argumentos?

É necessário, também, escolher um formato para a apresentação dos posicionamentos dos personagens sobre o tema em discussão. As atividades de representação de papéis podem ser desenvolvidas através dos seguintes formatos:

a) um fórum aberto com um moderador, onde qualquer um que queira falar pode fazê-lo por determinado tempo, quando indicado pelo moderador; 
b)

uma discussão em mesa redonda, com um determinado tempo

de fala para cada um dos oradores, seguido da confrontação entre posições antagônicas; e

c) uma sala forense, com um juiz e um júri externo, onde as apresentações devem ser feitas com um tempo determinado para os argumentos de cada posição, algum tempo para exames e refutações e, por fim, um tempo para os argumentos de encerramento.

As regras do jogo devem, também, ser acordadas entre alunos(as) e professor(a) de forma a descrever os procedimentos de votação das propostas que visem a resolver o assunto. Os votos podem ser individuais, por delegação ou feitos pelo júri externo. É necessário, ainda, tomar algumas decisões sobre a apuração desses votos para decidir a resolução a ser tomada pelos participantes do jogo. A resolução pode depender de maioria simples ou de uma maioria significativa, como por exemplo, de dois-terços dos votos.

Em resumo, a estratégia de jogo de representação de papéis propicia a aprendizagem de habilidades, tais como resolução de problema, comunicação e autoconsciência (Blatner, 2002). Compreende-se que tais habilidades seriam necessárias para um pensamento flexível, auto-expressivo, recursivo (com feedback) e de tomada de risco, que são, justamente, os processos de pensamento mais próximos às demandas das soluções de problemas complexos, como os ambientais, por exemplo. Embora esteja implícito nos parágrafos anteriores, queremos ressaltar que a elaboração e o desenvolvimento das atividades de representação de papéis envolvem o protagonismo do(a) professor(a), ou seja, o objeto de aprendizagem é um material de apoio para a ação dos(as) professores(as) que realiza a educação escolar, com o ensino de conteúdos escolares e de conceitos científicos. Por fim, é importante ressaltar que se entende que os(as) estudantes que participam em atividades de representação de papéis percebem que, por exemplo, os problemas relacionados ao sistema elétrico de um país são complexos e que não existem soluções simples.

Orientações para futuras pesquisas e desenvolvimento de novos produtos

Neste artigo, apresentamos o objeto de aprendizagem Energos, indicando algumas características de seu projeto pedagógico, realizando uma breve análise dos problemas enfrentados durantes sua implementação computacional e, por fim, sugerindo uma estratégia didática para a sua utilização em contexto escolar. Além disso, nesse espaço, queremos apresentar a continuidade de nossas atividades de produção de materiais didáticos computacionais, através de um projeto financiado pela FINEP: Energos Plus.

Em Energos Plus pretendemos criar um módulo de edição de novas atividades. Nesse sentido, imagina-se que professores(as) e alunos(as) que queiram buscar uma discussão temática sobre as emergências ambientais, por exemplo, possam utilizar Energos Plus para desenvolver cenários de suporte a tais discussões. Diversos tipos de paisagem poderiam fazer parte desses cenários, por exemplo: urbana, rural, litorânea e montanhosa. As atividades pedagógicas relacionadas a esses cenários poderão ser: resolução de problemas e jogos de representação de papéis.

Nesse sentido, o usuário de Energos Plus, poderá escolher entre as seguintes alternativas para a criação de novas atividades:

a) escolha da paisagem: ao usuário serão oferecidas ilustrações que possibilitem a ambientação e contextualização da atividade que se proponha a desenvolver. Serão oferecidas 5 paisagens de macrorregiões e 10 paisagens de microrregiões. 
b) escolha do tipo de atividade:

b.1) resolução de problemas: será oferecido ao usuário diversas máscaras de grade que poderão ser subscritas às ilustrações dos cenários. Através de um banco de dados serão alimentadas as informações relacionadas à grade. Essas informações poderão ser textos curtos ou valores de unidades que, também, devem ser fornecidas pelo usuário. Por exemplo, se um professor pretende criar um cenário visando o debate sobre os agrotóxicos no meio ambiente, ele pode escolher uma paisagem de uma microrregião de transição entre o rural e o urbano, escolher uma máscara de grade que reflita essa transição, alimentar o banco de dados com as unidades de concentração de agrotóxicos (p.ex., organofosforados ou carbamatos) e estipular diferentes concentrações para as diversas células da grade. Nesse exemplo, os alunos, poderiam vir a pesquisar a concentração de agrotóxicos em diferentes locais da paisagem. Esse tipo de atividade é similar àquela que desenvolvemos no software Carbópolis (Eichler e Del Pino, 2000).

b.2) jogo de representação de papéis: as mesmas ilustrações estariam a disposição dos usuários. Além disso, seria oferecido um módulo de edição de personagens, contendo figuras masculinas e femininas. O usuário poderá editar um determinado número de personagens (escolhendo gênero, etnia e vestimentas) que serão inseridos em diferentes locais da paisagem. Nesse tipo de atividade, os usuários devem indicar os depoimentos desses personagens em relação à temática que esteja em discussão. Por exemplo, se um professor pretende criar um cenário visando o debate sobre os alimentos geneticamente modificados, pode escolher uma paisagem de uma macrorregião, depois solicitar que os alunos montem os personagens e que indique os depoimentos que os personagens fariam sobre o tema em debate. A montagem inicial desse cenário serve de suporte para os jogos de representação de papéis, conforme atividade similar que desenvolvemos no software Cidade do Átomo (Eichler, Junges e Del Pino, 2006).

Posteriormente, conforme realizamos com Carbópolis (Eichler e Del Pino, 2006), após uma ampla divulgação, junto aos sistemas escolares, dos objetos de aprendizagem, softwares educativos e ambientes de aprendizagem produzidos, pretendemos verificar como esse tipo de material didático é efetivamente utilizado em contexto escolar, principalmente em relação às estratégias didáticas utilizadas pelos(as) professores(as).

Referências:

BLATNER, A. Role playing in education. Versão de 2002, disponível em: $<$ http://www.blatner.com/adam/pdntbk/rlplayedu.htm>. Acesso em: 18/03/2005.

BONNET, C. The relevance of role-playing in environmental education. Em: International Symposium BioEd, Paris, 12 -15 Maio de 2000. Disponível em: $<$ http://www.iubs.org/cbe/cbe_paper_index.html>. Acessado em: 18/03/2005.

BRASIL. Orientações curriculares para o ensino médio ; volume 2: Ciências da natureza e suas tecnologias. Brasília: MEC/SEB, 2006a.

BRASIL. Orientações curriculares para o ensino médio ; volume 3: Ciências humanas e suas tecnologias. Brasília: MEC/SEB, 2006b.

BRASIL. Parâmetros Curriculares Nacionais: meio ambiente. Brasília: MEC/SEF, 1998.

BRASIL. Parâmetros Curriculares Nacionais: meio ambiente. Brasília: MEC/SEF, 2001. 
CRONIN-JONES, L. Science scenarios: using role-playing to make science more meaningful. The Science Teacher, 67 (4), 48-52, 2000.

DUVEEN, J. \& SOLOMON, J. The great evolution trial: use of role-play in the classroom. Journal of Research in Science Teaching, 31 (5), 575-582, 1994.

EICHLER, M.L. \& DEL PINO, J.C. Carbópolis, um software para educação química. Química Nova na Escola, 11, 10-12, 2000.

EICHLER, M.L. \& DEL PINO, J.C. Ambientes virtuais de aprendizagem: desenvolvimento e avaliação de um projeto em educação ambiental. Porto Alegre: Editora da UFRGS, 2006.

EICHLER, M.L.; GONÇALVES, M.R.; SILVA, F.O.M.; JUNGES, F.; DEL PINO, J.C. Uma proposta para o desenho interdisciplinar de ambientes virtuais de aprendizagem de ciências. RENOTE - Revista Novas Tecnologias de Educação, $1(2), 2003$.

EICHLER, M.L.; JUNGES, F.; DEL PINO, J.C. O papel do jogo no ensino de radioatividade: os softwares Urânio-235 e Cidade do Átomo. Renote - Revista Novas Tecnologias na Educação, 3 (1), 2005.

EICHLER, M.L.; JUNGES, F.; DEL PINO, J.C. Cidade do Átomo, um software para o debate escolar sobre energia nuclear. A Física na Escola, 7 (1), 2006.

GONÇALVES, M.R.; EICHLER, M.L.; DEL PINO, J.C. Modelagem de um sistema elétrico para o ambiente virtual de aprendizagem Energos. Revista Geonotas, 7 (2), 2003

GONÇALVES, M.R.; EICHLER, M.L; DEL PINO, J.C. Elaboração de mapas para o desenvolvimento de ambientes virtuais de aprendizagem para a educação científica. Boletim Gaúcho de Geografia, 28 (1), 95-109, 2002.

JACKSON, P.T. \& WALTERS, J.P. Role-playing in analytical chemistry: the alumni speak. Journal of Chemical Education, 77 (8), 1019-1024, 2000.

MAIER, H.W. Role playing: Structures and educcational objectives. Journal of Child and Youth Care, 6 (4): 145-150, 1991.

MOOCK, C. Essential ActionScript 2.0. Sebastopol (Califórnia): O’Reilly Media, Inc., 2004

NEVES, I.C.B.; SOUZA, J.V.; SCHÄFFER, N.O.; GUEDES, P.L. e KLÜSENER, R. Ler e escrever: compromisso de todas as áreas. Porto Alegre: Editora da UFRGS, 1998.

TRUMBORE, C.R. A role-playing exercise in general chemistry. Journal of Chemical Education, 51 (2), 117-118, 1974.

WHISNANT, D.M. A role-playing exercise using a computer simulation. Journal of Chemical Education, 69 (1), 42-43, 1992. 